\title{
JOURNAL.RU
}

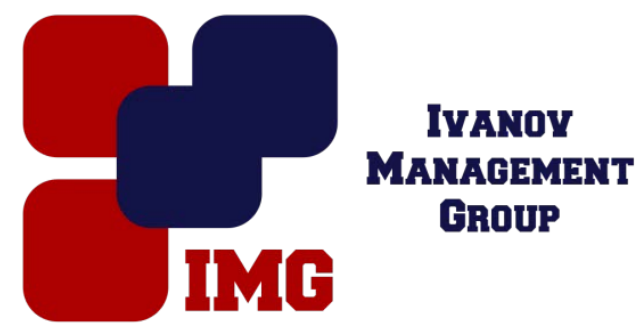

Скрылева Д. Д. Самарский Государственный Экономический Университет Самара, Россия

doi: 10.18411/lj-31-01-2017-2-07

idsp 000001:lj-31-01-2017-2-07

\section{Применение методов теории массового обслуживания для оценки качества обслуживания в отделениях банка}

\section{Аннотация}

В данной работе были рассмотрены основные понятия теории массового обслуживания,а также произволен анализ работы трех отделений банка. На основании этого сформулирован вывод о эффективности работы каждого отделения и даны краткие рекомендации по улучшению эффективности работы данного отделения.

Ключевые слова: теория массового обслуживания, вероятность, клиенты, отделение, заявки, интенсивность, эффективность.

Теория массового обслуживания - это прикладная область теории случайных процессов, которые в случайные моменты времени извне или изнутри поступают заявки (требования). Они должны тем или иным образом быть обслужены системой. Длительность обслуживания чаще всего случайна.Предметом изучения теории массового обслуживания являются систем массового обслуживания $(\mathrm{CMO})$. Цель теории массового обслуживания выработка рекомендаций по рациональному построению СМО, рациональной организации их работы и регулированию потока заявок для обеспечения высокой эффективности функционирования СМО. Для достижения этой цели ставятся задачи теории массового обслуживания, состоящие в установлении зависимостей эффективности функционирования СМО от ее организации (параметров): характера потока заявок, числа каналов и их производительности и правил работы СMO. 


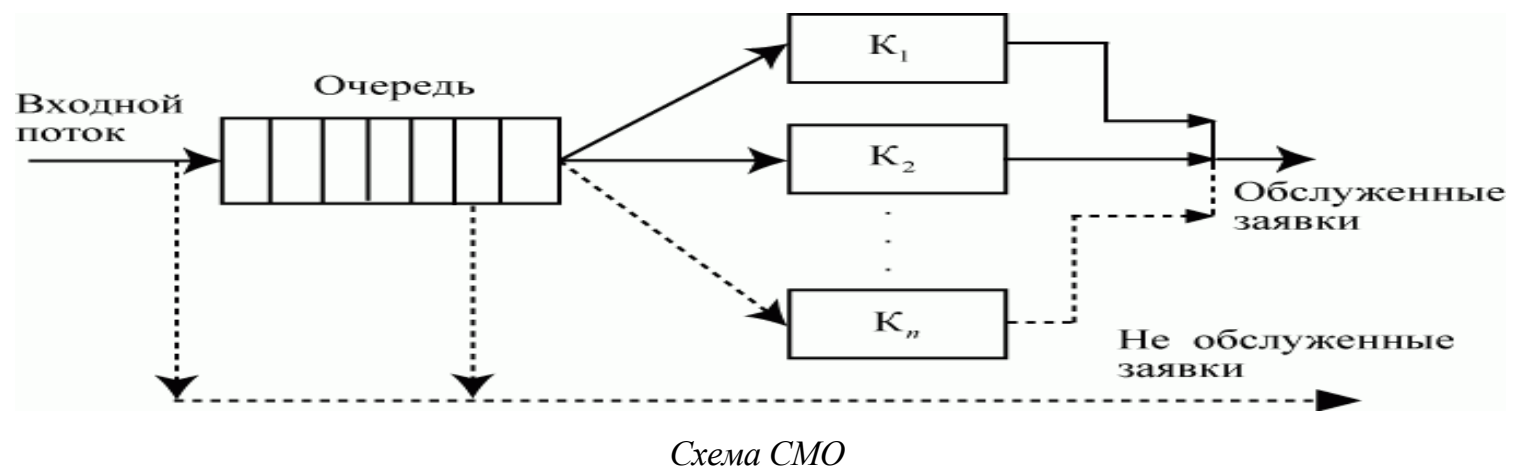

Таким образом, Смо состоит из таких элементов как: Входящий поток заявок на обслуживание, Очередь заявок, ожидающих обслуживание, каналы обслуживания, выходящий поток обслуженных заявок, поток не обслуженных заявок.

Для того,чтобы рассчитать вероятность отсутствия посетителей в банке воспользуемся формулой: $p_{0}=\left(1+\frac{\rho}{1 !}+\frac{\rho^{2}}{2 !}+\ldots+\frac{\rho^{n-1}}{(n-1) !}+\frac{\rho^{n}}{(n-1) !} \cdot \frac{1}{n-\rho}\right)^{-1}$.

Для определения вероятности образования очереди:

$$
p_{\text {оч }}=\frac{\rho^{n}}{n !} \cdot \frac{n}{n-\rho} \cdot p_{0}
$$

Среднее число посетителей в очереди: $L_{o u}=\frac{\rho^{n+1}}{n !} \cdot \frac{n}{(n-\rho)^{2}} p_{0}$

Среднее число обслуживаемых заявок:

$L_{\text {обс }}=\rho$.

Среднее число посетителей (обслуживаемых и в очереди) равно Lcмо = Lоч + Loбc

Среднее время, затрачиваемое посетителем на получение услуги: $\bar{t}_{\text {смо }}=\frac{L_{\text {оч }}}{\lambda}+\frac{Q}{\mu}$

Рассмотрим применение аналитического метода теории массового обслуживания на примере деятельности трех отделения коммерческого банка.Для определения показателей эффективности отделений банка были определены исходные данные, выявленные в ходе наблюдения за обслуживанием клиентов в течение месяца, рассчитанные как среднее арифметическое значений, полученных за каждый день месяца. За единицу времени принимается один час рабочего дня.

Отделение банка № 1:

число специалистов (n) - 6;Интенсивность потока посетителей 55 человек в час. Среднее время обслуживания одним специалистом одного требования клиента ( $\mathrm{t}$ об) - 4,8 мин $(0,08$ ч);

Имеем, $\mathrm{n}=6, \lambda=55$ ч/час $\wedge(-1)=0,92$ ч/мин $\wedge(-1), \mu=0,21 /$ мин $^{\wedge}(-1), \rho($ коэффициент загрузки) $=\lambda / \mu=4,38$ 
Таблица 1

Характеристики работы отделения банка №1

\begin{tabular}{|c|c|}
\hline Вероятность отсутствия посетителей в банке & $\mathrm{p} 0=0,0106$ \\
\hline Вероятность образования очереди & Poч= 0,385 \\
\hline Среднее число посетителей в очереди & Loбс $=4,38409$ \\
\hline Среднее число обслуживаемых заявок & равно Lcмо $=$ Loч + Loбс $\approx 1,0409+4,38=5,4209$ \\
\hline $\begin{array}{c}\text { Среднее число посетителей (обслуживаемых и в } \\
\text { очереди) }\end{array}$ &
\end{tabular}

T.e. работники банка практически всё время заняты.Получается,на каждого работника меньше одного клиента, что не оптимально. (не оптимально для банка,но оптимально для посетителей).Среднее время, затрачиваемое посетителем на получение услуги $=5.836318$ что не очень много. Можно сделать вывод, что работа банка организована достаточно эффективно. Рекомендаций по улучшению эффективности не требуется.

Для сравнения рассчитаем эффективность работы другого отделения банка.

Количество специалистов (n) = 7, Интенсивность потока посетителей 96 человека в час. Среднее время обслуживания одним специалистом одного требования клиента (t об)- 3,4 мин.Имеем, $\mathrm{n}=7, \lambda=96$ ч/час $\wedge(-1)=1,6$ ч/мин ${ }^{\wedge}(-$ $1), \mu=0,29$ ч $/$ мин $^{\wedge}(-1), \rho($ коэффициент загрузки $)=\lambda / \mu=5,5$

Характеристики работы отделения банка №2

\begin{tabular}{|c|c|}
\hline Вероятность отсутствия посетителей в банке & $\mathrm{p} 0=0,0053$ \\
\hline Вероятность образования очереди & Роч=0,747 \\
\hline Среднее число посетителей в очереди & $\mathrm{Loq}=2,7394$ \\
\hline Среднее число обслуживаемых заявок & $\mathrm{Loбc}=5,5$ \\
\hline $\begin{array}{c}\text { Среднее число посетителей (обслуживаемых и в } \\
\text { очереди) }\end{array}$ & $\mathrm{Lcmo}=2,7394+5,5 \approx 8,2394$ \\
\hline
\end{tabular}

Получается, что работники банка практически всё время заняты.То есть на каждого работника меньше одного клиента в очереди, что не оптимально.Среднее время, затрачиваемое посетителем на получение услуги банка $=5,16$ что не много и оптимально. Несмотря на это, если слегка уменьшить время обработки одного запроса клиента, то работа отделения станет эффективнее.

Такие же расчёты произведем для 3 отделения банка, в котором работает 5 сотрудников, интенсивность потока посетителей $=20$ в час, а среднее время обслуживания 1 клиента=7,1 минута.

Имеем, $\mathrm{n}=5, \lambda=20$ ч/час ${ }^{\wedge}(-1)=0,3$ ч/мин ${ }^{\wedge}(-1), \mu=0,14$ ч $/$ мин $^{\wedge}(-1), \rho($ коэффициент загрузки) $=\lambda / \mu=2,1$

Таблицุа 3

Характеристики работы отделения банка №3

\begin{tabular}{|c|c|}
\hline Вероятность отсутствия посетителей в банке & $\mathrm{p} 0=0,125$ \\
\hline Вероятность образования очереди & Роч $=0,07$ \\
\hline Среднее число посетителей в очереди & Loч $=0,053$ \\
\hline Среднее число обслуживаемых заявок & Loбс $=2,1$ \\
\hline $\begin{array}{c}\text { Среднее число посетителей (обслуживаемых и в } \\
\text { очереди) }\end{array}$ & $\mathrm{Lcmo}=2.1+0,053=2,153$ \\
\hline
\end{tabular}


Получается, что работники банка свободны 12,5 \% своего рабочего времени.Значит, на 5 сотрудников приходится всего 2 клиента, что очень мало. Работа центра организована неэффективно.Среднее время, затрачиваемое посетителем на получение услуги банка $=0,18$ что очень мало.Работа абсолютно неэффективна. Для улучшения эффективности необходимо уменьшить количество работников.

Таким образом, можно сделать вывод, что работа отделений банка в большинстве своем организована оптимально для клиентов. Они не долго простаивают в очередях, и оперативно получают свои услуги. Не смотря на это, организация работы самих банков выполнена не очень оптимально. В 1 из трех проверенных нами отделений, все работники 12,5 \% своего рабочего времени вообще не заняты работой.

\section{Литература}

1. В.А. ПавскийТЕОРИЯ МАССОВОГО ОБСЛУЖИВАНИЯ, Учебное пособиеДля студентов вузов, Кемерово 2008, 116 стр.

2. К. Л. САМАРОВУчебное пособие для студентовЭЛЕМЕНТЫ ТЕОРИИ МАССОВОГО ОБСЛУЖИВАНИЯ ,2013 г., 130 стр. 